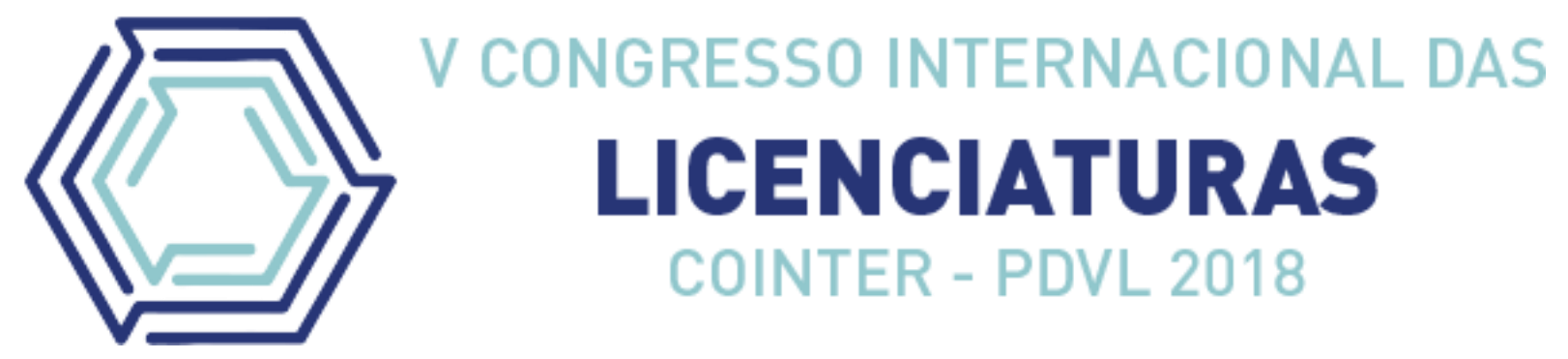

\title{
CONCEPÇÕES QUÍMICAS SOBRE EVOLUÇÃO DOS MODELOS ATÔMICOS DOS ALUNOS DO ENSINO MÉDIO.
}

\section{CHEMIESE BEGRIPPE OOR EVOLUSIE VAN ATOOMKRAG MODELLE VAN MIDDELBARE SKOOL STUDENTE}

Apresentação: Pôster

\author{
João Sandry de Moura Feitosa ${ }^{1}$; Raiany Fernanda Rodrigues ${ }^{2}$; Francisco de Assis \\ Pereira Neto ${ }^{3}$
}

\section{DOI: $\underline{\text { https://doi.org/10.31692/2358-9728.VCOINTERPDVL.2018.00189 }}$}

\section{Introdução}

A evolução dos modelos atômicos é fundamental para a compreensão do átomo e de como ele se comporta na natureza. Desta forma é importante analisar se os alunos têm a concepção do porque dessa evolução, atrelada ao contexto histórico da ciência, bem como suas implicâncias não só para o desenvolvimento desta, mas para a vida das pessoas.

O presente estudo centra-se na evolução dos modelos atômicos, voltado para a concepção dos alunos, uma vez que esses modelos dependem fortemente dos conhecimentos e da imaginação de quem o está a construir. Quanto mais profundos são os conhecimentos e quanto maior é a imaginação do idealizador, mais perfeito será o modelo. São, portanto, os modelos, uma ponte entre o conhecido e o desconhecido. Um bom modelo conduz, assim, a mais conhecimentos.

Neste sentido, este trabalho aplicou um questionário em três turmas de Ensino Médio em uma escola estadual localizada na cidade de Sussuapara-PI, com objetivo de avaliar as concepções que os alunos possuem a respeito do conteúdo envolvendo modelos atômicos e sua evolução histórica, visando avaliar as principais dificuldades que os alunos enfrentam ao estudar um tema que, muitas vezes, é visto de forma aparente sem abordar, na maioria das vezes, o contexto histórico e a evolução dos modelos a partir das descobertas científicas da época.

\footnotetext{
1 Licenciatura em Química, Instituto Federal do Piauí-IFPI, joaosandry8@gmail.com

${ }^{2}$ Licenciatura em Química, Instituto Federal do Piauí-IFPI, raianyfer20@hotmail.com

${ }^{3}$ Mestre em Química, Instituto Federal do Piauí-IFPI, francisco.pereira@if.pi.edu.br
} 


\section{Fundamentação Teórica}

De acordo com Pires e Ribeiro (2008), a constituição da matéria é um tema que já intrigava os filósofos da Grécia antiga e que continua a ser investigado pelos cientistas da atualidade. Ao longo dos anos, várias foram às investigações e experiências que colaboraram para o avanço do conhecimento da constituição da matéria, principalmente os espetros de emissão atómica, também foi o maior motor de longos avanços em relação ao conhecimento humano a respeito da estrutura da matéria, impondo a um passo de gigante na formação do modelo atómico (MAGALHÃES, 2007).

Os modelos dependem fortemente dos conhecimentos e da imaginação de quem o está a construir. Quanto mais profundos são os conhecimentos e quanto maior é a imaginação do idealizador, mais perfeito será o modelo. São, portanto, os modelos, uma ponte entre o conhecido e o desconhecido. Um bom modelo conduz, assim, a mais conhecimentos (SILVA, 2013).

Assim, no transcorrer da história da Ciência, vários modelos atômicos e teorias foram formados e considerados aceitáveis para explanar diversos fenômenos. Pesquisas realizadas posteriormente mostraram que essas explicações tinham caráter provisório, de forma a modificar ou mesmo refutar as ideias anteriores, ou reconhecer sua validade para uma menor gama processual propondo modelos e teorias adequados (LIMA; NUÑEZ, 2004).

Nesse sentido, para os alunos de Ensino Médio, é de grande importância compreender o contexto histórico em que relata o desenvolvimento do atomismo desde seus primeiros modelos atômicos, pois isso ajuda a entender a evolução do conceito atômico ao longo da história (GATTO; JUNIOR; STANZANI, 2017).

\section{Metodologia}

Esta pesquisa é do tipo quali-quantitativa, sendo esta um estudo de caso. A mesma foi desenvolvida em três turmas de terceiro ano do Ensino Médio totalizando 80 na Unidade Escolar Helvídeo Nunes, localizada na cidade de Sussuapara - PI. Os dados da pesquisa foram coletados por meio de um questionário elaborado de forma autoral, contendo cinco questões, que discorriam sobre a representação dos modelos atômicos, o nível de conhecimento dos alunos sobre o modelo atômico mais atual, a evolução dos modelos atômicos e o estudo da mesma em sala de aula. 
O questionário foi aplicado individualmente, durante 40 minutos, que é a duração de uma hora aula na escola em questão. Além disso, os alunos foram avisados previamente que não poderiam consultar material, pois por serem alunos do último ano do ensino médio, esperava-se que estes dominassem bem o conteúdo em questão. Após a aplicação os dados foram tratados para fins dessa pesquisa.

\section{Resultados e Discussões}

A seguir são apresentados os resultados para as cinco questões aplicadas aos alunos. Inicialmente pediu-se aos aos alunos que desenhassem os modelos atômicos dos cientistas Dalton, Thomson, Rutherford e Bohr, uma vez que estes modelos, são os mais abordados pelos os livros de química do ensino médio.

Nessa questão, foi pedido que os alunos desenhassem a representação dos modelos atômicos propostos por cada pesquisador acima citado. Muitos alunos responderam "não sei"ou "não lembro" ou deixaram essa questão em branco. Mas, mesmo assim a maioria tentou responder.

Figura 1: Algumas representaçoes dos modelos feitas por quatro alunos. Fonte: Própria.

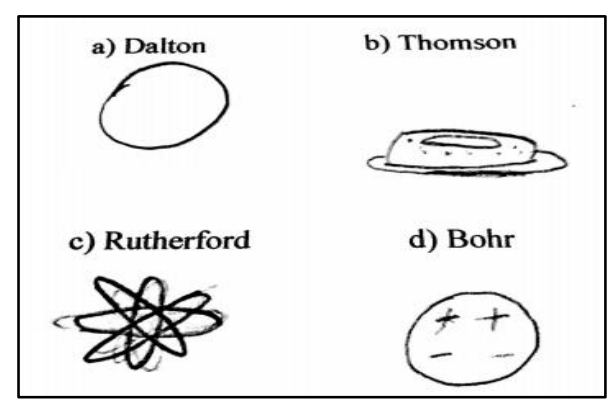

Nota-se que os alunos tiveram maior facilidade para representar corretamente o modelo atômico proposto por Dalton (Figura 1a). No entanto, nas representações dos modelos propostos por Thomson (Figura 1b), Rutherford (Figura 1c) e Bohr (Figura 1d) houveram algumas incoerências o que pode significar maior dificuldade.

O modelo atômico de Dalton, por ser o mais simples, pode ter contribuído para esse alto índice de representações corretas. Isto mostra que à media que os conceitos envolvidos ficam mais complexos, há uma maior dificuldade em representa-los, pois como afirmam Andrade e Razuck (2014), o nível de abstração dos modelos atômicos provoca dificuldades de visualização nos alunos, aumentando assim sua capacidade de compreensão fazendo com que os mesmos expliquem tais modelos de maneira errônea. Isso justifica as representações incorretas para os demais modelos. 
Na segunda questão, foi realizada a seguinte pergunta: "Você conhece o modelo atômico mais atual? Se sim comente sobre o mesmo". Essa questão foi elaborada com o intuito de saber se os alunos possuíam um conhecimento prévio sobre a evolução dos modelos atômicos e qual era o modelo mais atual. Dos respondentes um total de 18 disseram que conheciam o modelo ou ja tinham ouvido falar, enquanto que os 62 restantes deixaram em branco. O Quadro 1 mostra algumas das definições dos alunos que comentaram sobre o modelo quântico (que é o mais aceito atualmente para descrever os átomos).

Quadro 1: Respostas da segunda questão. Fonte: Própria.

Aluno 1: "É um átomo como uma pequena partícula constituída por prótons, neutros e elétrons".

Aluno 2: "Subníveis onde possuem cargas positivas e negativas".

Aluno 3: "É o modelo que fala dos orbitais".

Aluno 4: "O modelo atual é o mais completo entre os modelos, pois é onde se encontra os orbitais atômicos".

Aluno 5: "Modelo altamente complexo".

De acordo com Silva (2018), o modelo quântico é o mais aceito para representar o átomo e é chamado também de modelo de nuvem eletrônica. Este modelo indica que o átomo é formado por uma região central pequena, chamada de núcleo, que nele possui dois tipos de partículas, os prótons e os nêutrons, e envolta do núcleo existe uma região maior conhecida como nuvem eletrônica. Como pode-se notar na fala dos alunos, as definições são bastante incoerentes com o modelo quântico.

Para que o aluno compreenda os modelos atômicos é necessário que ele se esforce bastante intelectualmente, por isso há dificuldade de compreensão e isso faz com que os alunos apenas memorizem os modelos, pelo fato de muitas não conseguirem a conexão com outros conteúdos de química. Além disso, os professores também apresentam dificuldades no conteúdo de modelos atômicos, por causa da necessidade de contextualização atrelada as poucas possibilidades de diminuir o nível de abstração do conteúdo (SILVA; MACHADO; SILVEIRA, 2015).

A terceira pergunta foi: "Na sua opinião, por que os modelos atômicos foram modificados ao longo do tempo?". Para melhor desenvolvimento do trabalho, as respostas foram categorizadas de acordo com o grau de semelhança entre si, podendo o aluno apontar 
mais de

uma

\section{Por quê os modelos atômicos foram moficados ao longo do tempo?}

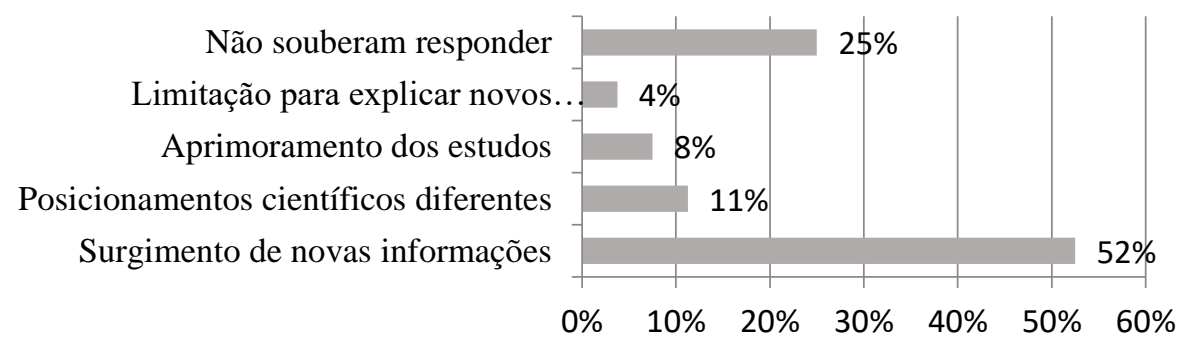

justificativa. A figura 2 ilustra os resultados.

Figura 2: Respostas da terceira questão. Fonte: Própria.

A grande dificuldade que os alunos possuem para conseguir explicar o porquê da evolução dos modelos atômicos é devido ao fato de que parte dos professores não trabalha essa evolução de forma clara, pois eles deviam propiciar e provocar o surgimento do questionamento de como a matéria se estrutura a partir da compreensão da evolução do modelo atômico, outro fator é que a maioria dos livros didáticos não dá com muita clareza essa evolução (MELO; LIMA NETO, 2013).

A última questão conteve a seguinte pergunta: "O contexto histórico dos modelos atômicos foi abordado no seu cotidiano escolar?". Um total de $30 \%$ dos alunos respondeu que sim, o contexto histórico foi abordado em sala de aula, enquanto que $70 \%$ não souberam responder ou deixaram em branco. Esses dados mostram que a abordagem em sala de aula não está sendo satisfatória, reforçando ainda mais a importância do entendimento da evolução dos modelos, que para Melo e Lima Neto (2013) possibilitou um aperfeiçoamento e surgimento de novas características para representação do átomo, sendo fundamental

\section{Conclusões}

Ao final da pesquisa, percebeu-se que grande quantidade de alunos não conseguiu representar corretamente os modelos solicitados, e isto pode estar relacionado com o grau de abstração dos conceitos, exigindo que métodos sejam trabalhados em sala de aula para que esse quadro seja contornado. Além disso, o fato de grande parte dos respondentes não saber o porquê da evolução desses modelos, sugere que os professores não estão trabalhando de forma clara essa evolução, e isso somado ao fato dos livros pouco fazerem essa relação pode 
acarretar na não compreensão do processo histórico que levou os modelos a mudarem, bem como suas características e limitações ao longo da história da Química.

\section{Referências}

ANDRADE, J. S.; RAZUCK, R. C. S. R. O Ensino de Modelos Atômicos no $9^{\circ}$ ano do Ensino Fundamental e Sua Abordagem nos Livros Didáticos de Ciências Aprovados pelo PNLD/2014. In: XVII Encontro Nacional de Ensino de Química, 2014, Ouro Preto - MG. Anais do Encontro Nacional de Ensino de Química, 2014.

GATTO, M. A.; JUNIOR, J. B. S.; STANZANI, E. L. Subsídios histórico-filosóficos para o ensino do modelo atômico de Dalton. ACTIO, v. 02, n. 01, p. 376-400, 2017.

LIMA, A. A.; NUÑEZ, I. B. Aprendizagem por modelos: utilizando modelos e analogias. In: Fundamentos do Ensino-Aprendizagem das Ciências Naturais e da Matemática. Porto Alegre: Sulina, 2004, p.245-264.

MAGALHÃES, J. Caderno de atividades laboratoriais - Química A $10^{\circ}$ ano. Carnaxide: Santillana, 2007.

MELO, M. R.; LIMA NETO, E. G. Dificuldades de Ensino e Aprendizagem dos Modelos Atômicos em Química. Química Nova na Escola, v.35, n.02, p. 112-122, 2013.

PIRES, I.; RIBEIRO, S. Universo da matéria: ciências fisico-quimicas, $9^{\circ}$ ano. Carnaxide: Santillana, 2008. 72p.

SILVA, A. J. C T. Evolução do conhecimento da estrutura atômica: relatório de estágio. Covilhã, 2013.

SILVA, C. A. Modelos Atômicos como objeto do saber no Ensino de Química: uma proposta metodológica baseada em elementos da Engenharia Didática. Feira de Santana, 2018. 117p. Dissertação (Mestrado em Astronomia). UEFS, 2018.

SILVA, G. R.; MACHADO, A. H.; SILVEIRA, K. P. Modelos para o Átomo: Atividades com a Utilização de Recursos Multimídia. Química Nova na Escola, v. 37, n.02, p.106-111, 2015. 